\title{
Comparison of Two Ultrasound-guided Plane Blocks for Pain and Postoperative Opioid Requirement in Lumbar Spine Fusion Surgery: A Prospective, Randomized, and Controlled Clinical Trial
}

\author{
Lizhen Wang · Ying Wu • Lianjie Dou • Ke Chen (D) · Yuesheng Liu • \\ Yuanhai Li
}

Received: June 9, 2021 / Accepted: July 16, 2021 / Published online: August 4, 2021

(C) The Author(s) 2021

\section{ABSTRACT}

Introduction: The erector spinae plane (ESP) block and thoracolumbar interfascial plane (TLIP) block were two novel plane blocks. The purpose of this study was to investigate TLIP block and ESP block on the effect of analgesic and opioid consumption in lumbar spine fusion surgery in the perioperative period.

Methods: Three hundred and four patients who suffered lumbar spine fusion were included and

Lizhen Wang and Ying Wu contributed equally to this manuscript.

Supplementary Information The online version contains supplementary material available at https:// doi.org/10.1007/s40122-021-00295-4.

\section{Wang}

Department of Anesthesiology, First Affiliated Hospital, University of Science and Technology of China, Hefei, China

L. Wang · Y. Wu · K. Chen $(\varangle) \cdot$ Y. Liu $\cdot$ Y. Li $(\varangle)$ Department of Anesthesiology, First Affiliated Hospital of Anhui Medical University, Hefei, Anhui, China

e-mail: hbchenke@163.com

Y. Li

e-mail: liyuanhai-1@163.com

L. Dou

Department of Maternal, Child and Adolescent Health, School of Public Health, Anhui Medical University, Hefei, China randomly divided into three groups: a control group $(n=102)$, an ESP block group $(n=100)$, and a TLIP block group $(n=102)$. We recorded the numerical rating scale (NRS) pain at movement and static during the postoperative $48 \mathrm{~h}$, opioid consumption, additional analgesic requirement, frequency of patient-controlled analgesia (PCA) compressions, Bruggemann Comfort Scale (BCS) score, side effects, duration of hospital stay, and the life quality score (LQS) after operation at 6 months.

Results: The patients in the ESP block group have better analgesia during $12-48 \mathrm{~h}$ postoperative time at static state, a lower frequency of PCA compressions at $24-48 \mathrm{~h}$ after surgery, and the opioid consumption in the PCA (sufentanil) were less than those in the TLIP block group $(P<0.05)$. However, the BCS and LQS scores were no different between the two plane block groups after surgery at 6 months. There was no difference in hospital stay and the incidence of side effect among the three groups.

Conclusions: Our results found that patients who suffered ESP block have better analgesic effects and less pain scores in static states and less frequency of PCA compression and opioid analgesic consumption compared with those that suffered TLIP block.

Trial Registration: ChiCTR1800019639.

Keywords: Plane block; Opioid consumption; Analgesia; Lumbar fusion surgery 


\section{Key Summary Points}

Patients with lumbar spine fusion always had serious surgery-related acute pain and chronic preoperative pain before the surgery. Until now, there have been no effective regional analgesia techniques that may help reduce the surgery-related acute pain of lumbar spine surgery.

Ultrasound-guided plane blocks are a new development in modern regional anesthesia research and practice, opening new ways for local anesthesia to be transmitted to various anatomic locations in recent years.

The erector spinae plane block and thoracolumbar interfascial plane block are two of the newest techniques developed in 2015-2016, and since then, publications referring to the two blocks have increased significantly.

\section{INTRODUCTION}

Patients with lumbar spine fusion have always had serious surgery-related acute pain and chronic preoperative pain before the surgery [1-4]. Until now, there have been no effective regional analgesia techniques to help reduce the surgery-related acute pain of lumbar spine surgery. Recent studies suggest that effective regional anesthesia techniques may help reduce the development of chronic pain and reduce the use of opioids advocated $[5,6]$. Novel plane blocks have been developed to improve the management of perioperative pain in the last decade due to the ease of application, low risk of complications, analgesic efficacy, and reduction of opioid consumption $[7,8]$. In particular, after the introduction of ultrasonography technology, many plane blocks have gained wide application in surgeries, including transversus abdominis plane block, pectoralis I and II blocks, serratus plane block, erector spinae plane block, rhomboid intercostal and subserratus block, and thoracolumbar interfascial plane (TLIP) block [9-12].

The erector spinae plane (ESP) block and TLIP block are the two newest techniques developed in 2015-2016, and since then, publications referring to the two blocks have increased significantly. The ESP block is performed by depositing the local anesthetic between the deep fascia of the erector spinae muscle and the transverse vertebral process [13], while the TLIP targets the fascial plane between the longissimus and iliocostalis muscles away from the midline [14]. Research has shown that both TLIP block and ESP block are useful in pain relief and reducing opioid consumption in lumbar surgery $[13,15,16]$. However, it is still unclear whether one block is superior to the other in terms of effectiveness of analgesia and side effects in lumbar fusion. To address this important gap in understanding, we conducted a comparison study of patients undergoing lumbar spine fusion surgery who received either ESP block or TLIP block as part of their analgesia management.

\section{METHODS}

Six hundred eighty-nine patients undergoing lumbar spine fusion surgery at the First Affiliated Hospital of Anhui Medical University were enrolled between November 1, 2018, and January 1,2020 . The study was approved by the Ethics Committee of First Affiliated Hospital of Anhui Medical University (No. PJ2018-11-01) and registered at the Chinese Clinical Trial Registry (ChiCTR1800019639). This study was performed in accordance with the Helsinki Declaration of 1964 and its later amendments. The data were collected by an anesthetist during the operation, and every patient was followed up by phone by the same nurse who was blinded to the entire experiments.

All of the patients signed consent forms and were randomly divided into three group (Group CON, Group ESP, and Group TLIP) according to a computer-generated random number and a 1:1:1 allocation ratio. The patients in Group ESP and Group TLIP were we suffered nerve plane 
block as part of analgesia, the patients in Group CON were not suffered nerve plane block. Patients with a history of severe psychiatric illness (major depression or generalized anxiety disorder), preplanned overnight hospitalization, pre-existing chronic pain (lasting at least 3 months), or being opioid-dependent with an average of more than $30 \mathrm{mg}$ of oxycodone per day or the equivalent were excluded.

General anesthesia was induced by intravenous propofol $(2-6 \mathrm{mg} / \mathrm{kg})$, sufentanil $(0.3-0.5 \mu \mathrm{g} / \mathrm{kg}), \quad$ and cisatracurium $(0.15-0.3 \mathrm{mg} / \mathrm{kg})$. During maintenance of general anesthesia, propofol (TCI, $1-2 \mathrm{ul} / \mathrm{kg}$ ), remifentanil $(0.15-0.3 \mu \mathrm{g} / \mathrm{kg} / \mathrm{min})$, and cisatracurium $(0.2 \mathrm{mg} / \mathrm{kg} / \mathrm{h})$ were used. After surgery, all patients were transferred to the postoperative recovery room and received patient-controlled analgesia (PCA) (sufentanil $4.5 \mu \mathrm{g} / \mathrm{kg}+$ flurbiprofen $\quad 100 \mathrm{mg}+$ saline $200 \mathrm{ml}$, background dose $3 \mathrm{ml} / \mathrm{h}$, self-control supplementary dose $3 \mathrm{ml}$, locking time $15 \mathrm{~min}$ ). When the numerical rating scale (NRS) score exceeded 5 at static state, patients were administered intravenous sufentanil $(5 \mu \mathrm{g})$ one or more times.

After general anesthesia was administered, the ESP block and TLIP block were performed before surgery in the operation room. The TLIP block was performed as described by Hand et al. [10]. A high-frequency linear transducer (EDGE; Sonosite, Bothell, WA, USA) was placed in the midline position at the third lumbar vertebra (L3), and $30 \mathrm{ml}$ of $0.375 \%$ ropivacaine was injected bilaterally into the interfascial plane between the longissimus muscle (LF) and multifidus muscles (MFs) of the patient. The ESP block was performed approximately, as described by Melvin et al. [17]. The appropriate T12 vertebral body level was determined by surface dissection or ultrasound, and a high-frequency linear array ultrasonic commutator was placed in the longitudinal sagittal position $3 \mathrm{~cm}$ from the midline to determine the tip of the transverse process. The needle pointed from a cranial to a caudal direction. After determining the correct position of the needle tip, $30 \mathrm{ml}$ of $0.375 \%$ ropivacaine was bilaterally administered for block performance (Fig. 1).
The primary outcomes of our interest were the NRS pain scores at movement state and static state and the total consumption of opioids at the perioperative period during the $48 \mathrm{~h}$.

The second outcomes of our interest include the side effects of opioids (nausea and vomiting, pruritus, respiratory depression), frequency of PCA compressions, remedial analgesic administration, and the life quality score during the 6 months after surgery.

Statistical analysis was performed using SPSS 23 software (SPSS Inc., Chicago, IL, USA) and GraphPad Prism 8.01 (GraphPad Software, San Diego, CA, USA). Calculations regarding the sample size were performed using an online power sample size calculator based on our previous pilot study data. Our previous pilot study shows that an effective frequency of PCA compressions number for patients under general anesthesia combined with TLIP block and ESP block (7.6 \pm 2.2 and $5.2 \pm 2.7$, respectively) as part of anesthesia after surgery. To detect differences in postoperative PCA compression use $48 \mathrm{~h}$ between the ESP block group and TLIP block group, the sample size was 78 per group at a power of $80 \%$ and a two-tailed $\alpha=0.05$. We asked 300 patients ( $n=100 /$ group) to participate in this study.

The ordinal variables are presented as the median and interquartile range. The categorical variables are presented as percentages. The object of baseline data such as age, height, and intraoperative drug dosage, operation time and postoperative press the number using singlefactor analysis of variance, and use of LSD method are compared, and two for sex, age, height, intraoperative drug dosage, operation time, and the comparison of postoperative complications such as infections, using a Chisquare test to explore the differences. Repeated measures analysis of variance was used to compare the changes in ASA scores between groups in experimental group TLIP, ESPB, and control group value with a probability lower than $\alpha=0.05$ was accepted as an indicator of significant differences between the groups. 


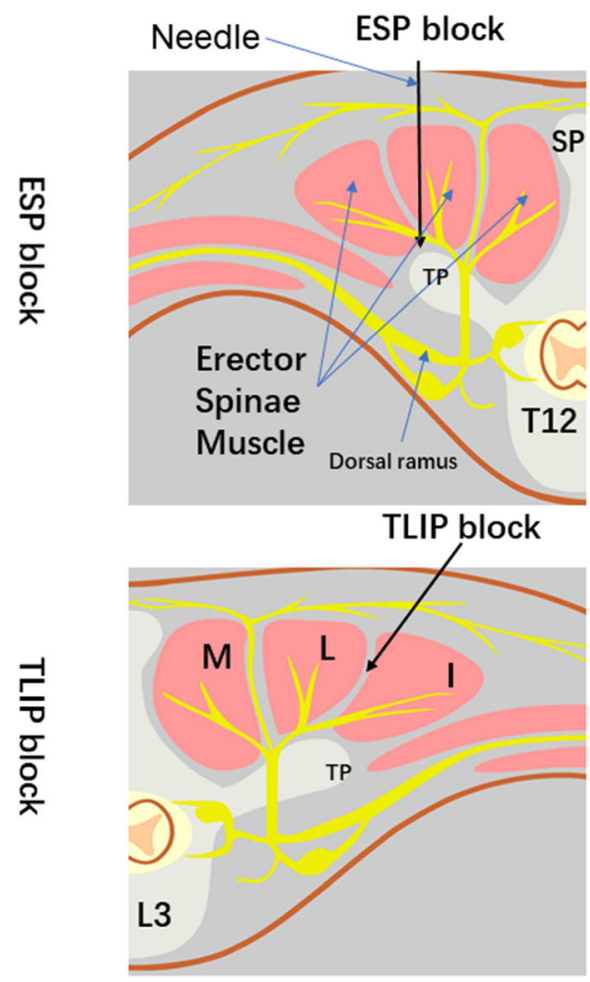

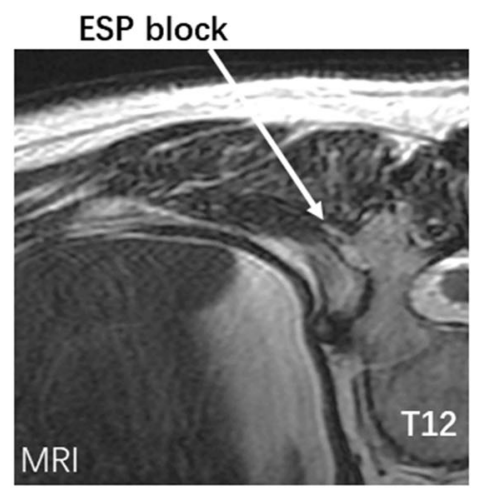

TLIP block

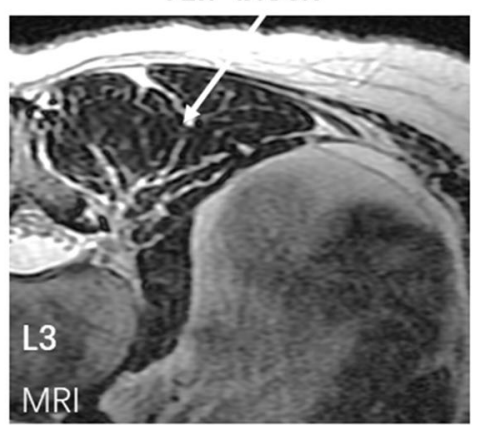

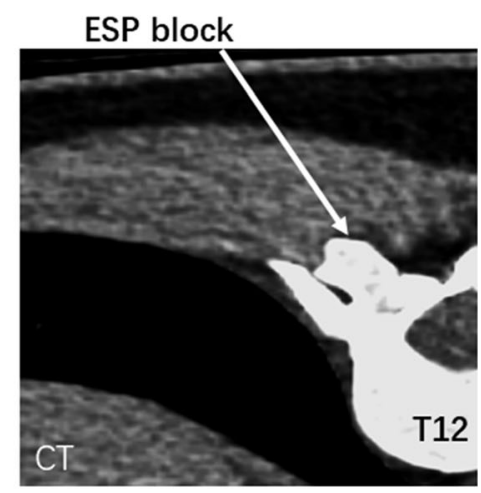

TLIP block

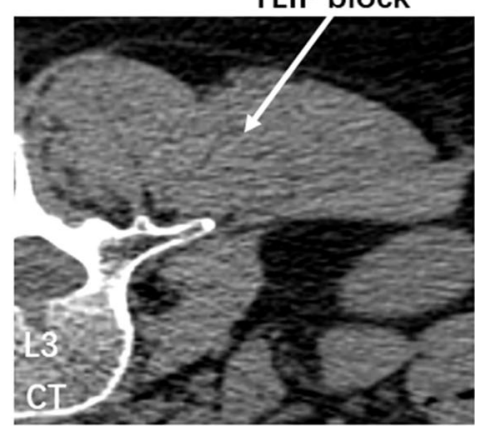

Fig. 1 Image of the spread of ESP block and TLIP block. Illustration landmarks and needle approach to the TLIP block and ESPB block. $L$ longissimus muscle, $I$ iliocostalis muscle, $M$ multifidus muscle, $T P$ transverse process, $S P$

\section{RESULTS}

\section{Participants Flow}

The Flow diagram (Fig. 2) shows that 689 patient charts were screened; 103 patients did not meet inclusion criteria, 134 patients had other surgical techniques, 137 patients declined to participate the experiments, and 13 patients were lost to follow-up. Three hundred and four patients were finally included in our studies; 100 were assigned Group CON, 102 to Group TLIP, and 102 to Group ESP.

In Table 1, we found that no significant differences in age, gender, surgical site, anesthesia duration, and surgery duration among the three groups. spinous process, ESPB erect spine plane block, TLIP thoracolumbar Interfascial plane. (Source credit part A: Ke Chen)

\section{Primary Outcome}

Opioid (sufentanil and remifentanil) consumption was less in Group ESP and Group TLIP compared with Group CON during the perioperative time $(P<0.05)$ and sufentanil consumption in PCA was decreased in Group ESP compared with Group TLIP $(P<0.05)$ (Table 2$)$.

The NRS scores during the $48 \mathrm{~h}$ postoperative period in Group ESP and Group TLIP were significantly lower than those in Group CON at the static state and movement state $(P<0.05)$. The static NRS scores of Group ESP have lower static NRS pain scores than those in Group at $12 \mathrm{~h}, 24 \mathrm{~h}$, and $48 \mathrm{~h}$ after surgery $(P<0.05)$, however, there is no difference at movement state between the two-block group during postoperative $48 \mathrm{~h}(\mathrm{P}>0.05)$ (Figs. 3,4$)$. 


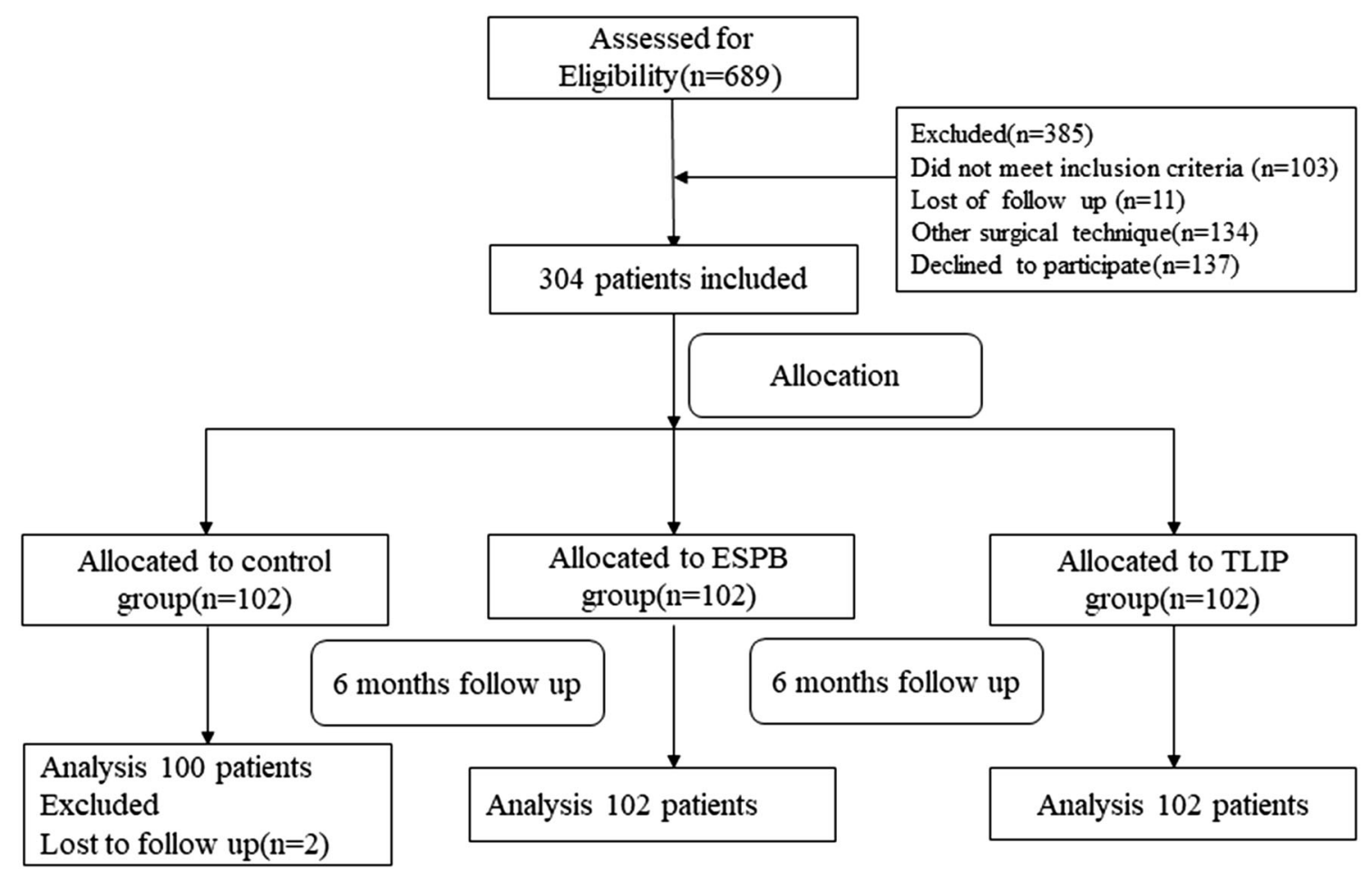

Fig. 2 CONSORT diagram

\section{Second Outcomes}

Both the patients in the ESP group and the TLIP group showed fewer PCA compressions and decreased amounts of remedial analgesia and shorter hospital stays than the patients in the control group $(P<0.01)$. The frequency of PCA compressions was decreased in Group ESP compared with Group TLIP at 24-48 h after surgery $(P<0.05)$ (Table 2$)$. The Bruggemann Comfort Scale (BCS) scores and life quality scores (LQS) after surgery showed no difference between the two plane groups, however, better than Group CON (Figs. 5, 6). The side effects of opioids (nausea and vomiting, pruritus, respiratory depression) were no difference among 3 groups (Table 3).

No statistically significant differences were found in the rate of side effects among the three groups.

\section{DISCUSSION}

Ultrasound-guided plane blocks are a new development in modern regional anesthesia research and practice in recent years, opening new ways for local anesthesia to be transmitted to various anatomic locations [7, 18]. Contrary to traditional peripheral regional anesthesia with defined neural endpoints, the exact targets of the plane blocks have not been well studied, and the indications are not well defined. Plane blocks can simply provide satisfactory consistent and sufficient analgesia when used in combination with multi-modal analgesic method in the context of enhanced recovery after surgery (ERAS) [19-21].

Lumbar fusion surgery is a classic conservative treatment method, which is to limit the progress of deformity and provides better relief [22]. However, spinal fusion surgery of the lumbar region causes severe postoperative pain, which affects rapid postoperative recovery. Although the number of spinal surgeries has increased in recent years, the options for 
Table 1 Demographic and characteristics of the patients

\begin{tabular}{llllll}
\hline Characteristic variable & CON group & TLIP group & ESP group & $\boldsymbol{F} / \chi^{2}$ & $\boldsymbol{P}$ value \\
\hline Age $($ years $)$ & $55.69 \pm 12.01$ & $52.73 \pm 12.08$ & $53.78 \pm 10.16$ & 1.736 & 0.178 \\
Height $(\mathrm{cm})$ & $164.93 \pm 11.5$ & $166.86 \pm 6.95$ & $164.03 \pm 6.94$ & 2.757 & 0.065 \\
Weight $(\mathrm{kg})$ & $64.13 \pm 10.45$ & $65.35 \pm 10.02$ & $64.78 \pm 9.93$ & 0.368 & 0.692 \\
BMI $\left(\mathrm{kg} / \mathrm{m}^{2}\right)$ & $24.28 \pm 11.26$ & $23.4 \pm 2.7$ & $24 \pm 2.71$ & 0.431 & 0.65 \\
Gender & & & & 4.469 & 0.107 \\
Male & $51(50)$ & $58(58)$ & $44(43.1)$ & & \\
Female & $51(50)$ & $42(42)$ & $58(56.9)$ & & \\
ASA & & & & & \\
1 & $11(10.8)$ & $16(16)$ & $21(20.6)$ & & \\
2 & $90(88.2)$ & $83(83)$ & $81(79.4)$ & & \\
3 & $1(1)$ & $1(1)$ & $0(0)$ & & \\
The operation section & & & & & \\
1 & $67(65.7)$ & $70(70)$ & $67(66.3)$ & & \\
2 & $31(30.4)$ & $28(28)$ & $33(32.7)$ & & \\
3 & $4(3.9)$ & $128.32 \pm 27.4$ & $127.29 \pm 30.45$ & 0.445 & 0.641 \\
Surgery time (min) & $130.92 \pm 26.91$ & $554.64 \pm 152.54$ & $565.78 \pm 145.06$ & 0.182 & 0.834 \\
Propofol & $565.89 \pm 158.39$ & $151.43 \pm 28.27$ & $148.67 \pm 30.88$ & 1.956 & 0.143 \\
Anesthesia time (min) & $156.58 \pm 27.7$ & & &
\end{tabular}

perioperative pain relief remain limited. The novel regional anesthetic techniques, including TLIP block and ESP block, have been performed for postoperative pain at lumbar surgery in recent years. Ciftci B found that both ESP block and mTLIP block provide adequate analgesia after lumbar discectomy surgery [23]. Our results found that patients who suffered ESP block have better analgesic effects and less pain scores in static states, less frequency of PCA compression, and less opioid analgesic consumption compared with those who suffered from TLIP block.

TLIP block targets the dorsal ramus and its branches exclusively in the lumbar distribution, which is the opposite of ESP block, which depends on local anesthetics craniocaudally diffusing from the plane, deep into the erector spinae muscles and superficial to the vertebrae (especially transverse process and intertransverse ligament) [24]. The local anesthetic in group ESP was injected in the ESP muscle avoids washout during the surgical procedure, and this translates to an increase in the quality and duration of analgesia, which will make patient analgesia last over $12 \mathrm{~h}[25,26]$. In our study, we found that the ESP block has a better quality of analgesia at static state during postoperative time than TLIP block. Possible explanations for these variations include the anatomic complexity of the thoracolumbar fascia, the volume of injectate administered, and differences in operator technique. These explanations indicate that the TLIP block is difficult to operate with the ESP block in spine fusion surgery and may not provide focused analgesia. 
Table 2 Comparison of opioid consummation, PCA compression, and postoperative recovery

\begin{tabular}{|c|c|c|c|c|c|c|}
\hline Characteristic variable & CON group & TLIP group & ESP group & $\boldsymbol{F}$ & $P$ value & $\begin{array}{l}P \text { for ESP and } \\
\text { TLIP }\end{array}$ \\
\hline Sufentanil at OR & $42.85 \pm 7.84$ & $27.82 \pm 3.88$ & $28.72 \pm 3.99$ & 233.376 & $<0.001$ & 0.249 \\
\hline Remifentanil & $1233 \pm 359.04$ & $329.62 \pm 365.73$ & $359.18 \pm 410.81$ & 186.078 & $<0.001$ & 0.58 \\
\hline Sufentanil in PCA & $192.38 \pm 31.34$ & $163.38 \pm 25.06$ & $126.38 \pm 18.86$ & 188.385 & $<0.001$ & $<0.001$ \\
\hline $\begin{array}{l}\text { PCA compressions } \\
(1-24 \mathrm{~h})\end{array}$ & $6.28 \pm 0.69$ & $3.9 \pm 0.67$ & $3.86 \pm 0.58$ & 458.725 & $<0.001$ & 0.684 \\
\hline $\begin{array}{l}\text { PCA compressions } \\
\quad(24-48 \mathrm{~h})\end{array}$ & $4.78 \pm 0.6$ & $3.28 \pm 0.78$ & $2.69 \pm 0.8$ & 222.087 & $<0.001$ & $<0.001$ \\
\hline \multicolumn{4}{|c|}{ Remedial analgesic administration } & 10.785 & 0.005 & $<0.05$ \\
\hline No & $71(69.6)$ & $83(83)$ & $90(88.2)$ & & & \\
\hline Yes & $31(30.4)$ & $17(15)$ & $12(11.8)$ & & & \\
\hline Hospital stay (days) & $5.56 \pm 0.57$ & $5.19 \pm 0.42$ & $5.17 \pm 0.4$ & 22.214 & $<0.001$ & 0.725 \\
\hline
\end{tabular}

$O R$ operation room, PCA patient-controlled analgesia

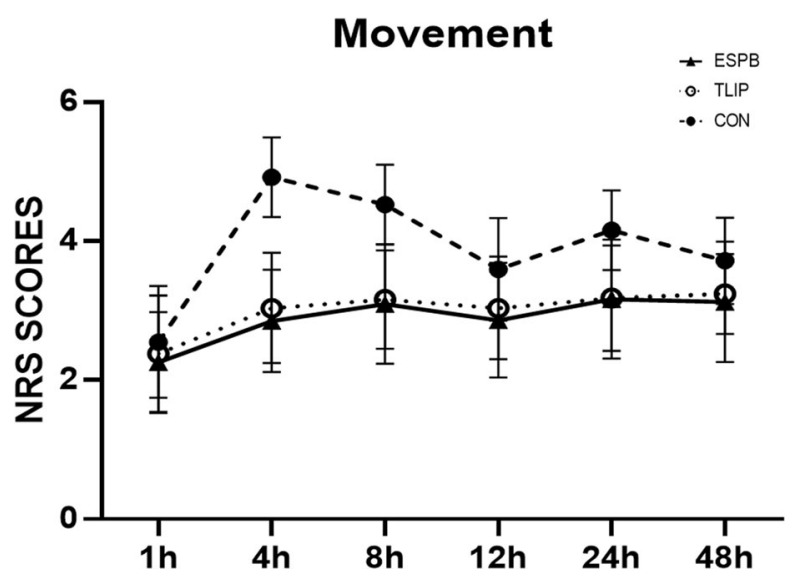

Fig. 3 NRS at movement state

Do ESP blocks provide more focused analgesia than TLIP blocks in lumbar spine surgery? Although the two plane blocks were described and performed for 5 years, many clinical and cadaveric studies have been devoted to the study of its mechanisms, but it is not clear. In near few years, many studies found that ESP block at T12 vertebrae could provide effective analgesia and reduce acute postoperative pain in lumbar surgery, because extensive analgesia could be obtained by depositing a volume of

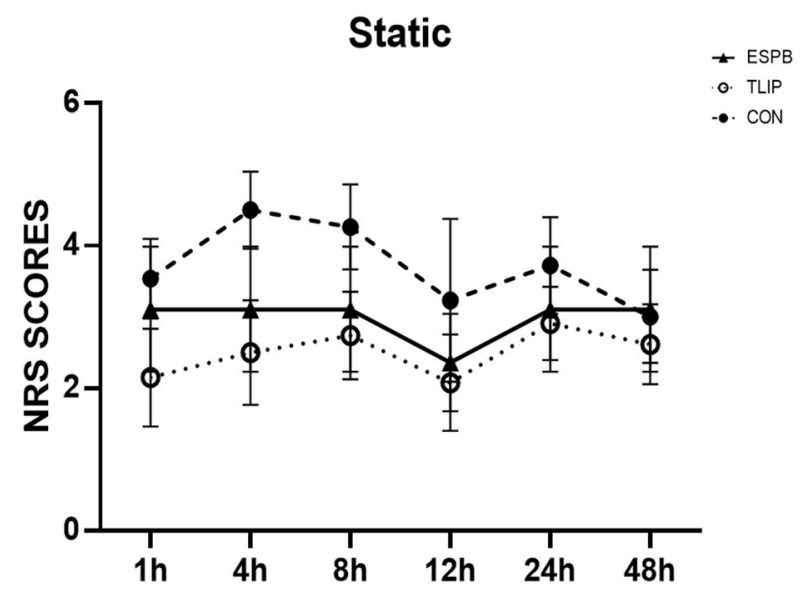

Fig. 4 NRS at static state

local anesthetic either superficial or deep to the erector spine muscle [27]. In our previous study, we found that ESP block could make the sensory loss to pinprick from the L1 spinous process to S2 spinous process and from left anterior axillary line to right anterior axillary line over the posterior lumbar, however, the scope of analgesia in TLIP block only from L1 to L4 and from left to right posterior axillary line. 


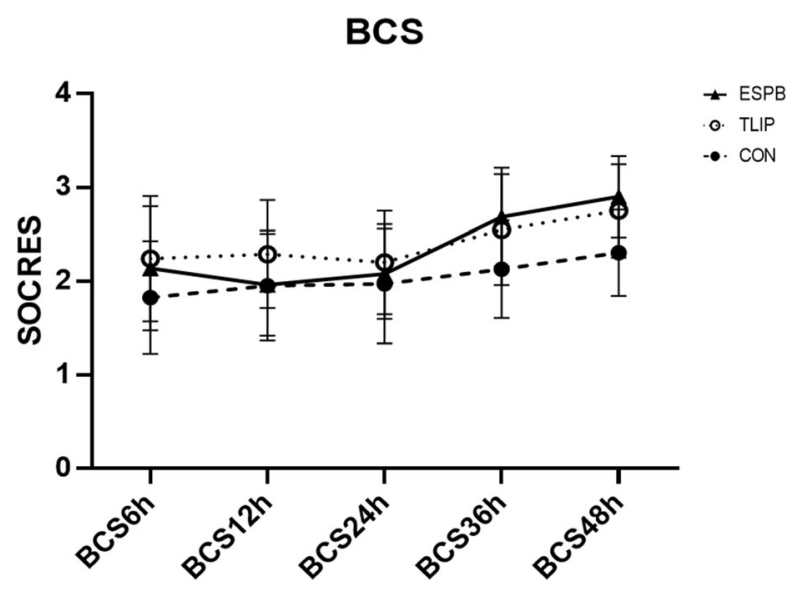

Fig. 5 Bruggemann Comfort Scale at post-operation

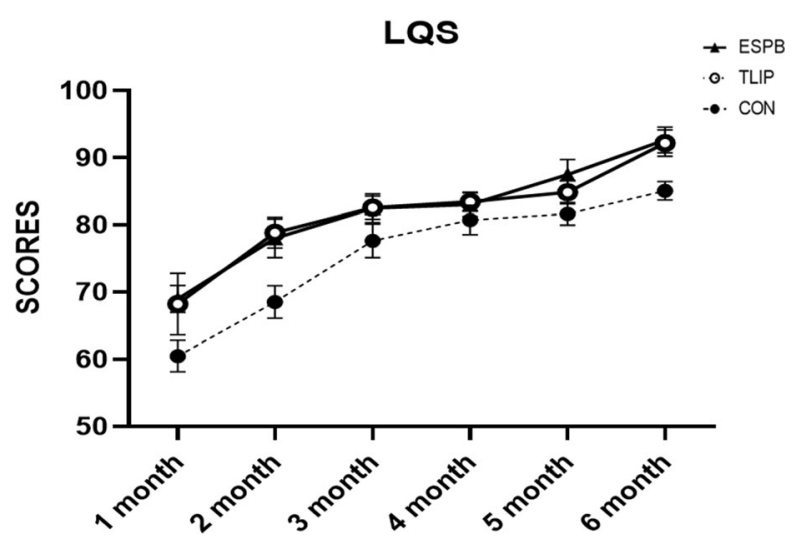

Fig. 6 The LQS scores at 6 months after operation
In order to allow patients to discharge more quickly after surgery and reduce the consumption of opioids, multi-modal analgesia, including regional blocks, was used to minimizing the consumption of other analgesics and their side effects. We found that the consumption of opioids decreased in ESP block compared with the TLIP group and the effective PCA compressions were significantly lower in the ESP block groups than those in the TLIP group. However, there were no differences between patient satisfaction and hospital stay. We also found that early effective regional anesthesia techniques during the perioperative period may help reduce the development of chronic pain and increase life quality compared with control group. However, based on the available evidence, at this point it is hard to argue that either technique is consistently superior for analgesia in lumbar spine surgery.

In addition, this capacity for extensive cranial-caudal diffusion is a unique advantage of the ESP block, which can be performed away from the surgical site, thereby minimizing the risk of microbial contamination. The distortion of the lumbar spine anatomy provoked by surgical intervention (interference due to edema, placement of hardware, bony element removal, or sutures) could interfere with the

Table 3 Comparison of side effects after operation

\begin{tabular}{lccccc}
\hline Characteristic variable & CON group & TLIP group & ESP group & $\chi^{2}$ & $P$ value \\
\hline Respiratory depression & & & & 0.684 & 0.71 \\
No & $95(93.1)$ & $95(95)$ & $94(92.2)$ & & \\
Yes & $7(6.9)$ & $5(5)$ & $8(7.8)$ & & \\
Skin pruritus & $92(90.2)$ & $94(94)$ & $98(96.1)$ & & 0.228 \\
No & $10(9.8)$ & $6(6)$ & $4(3.9)$ & & 0.38 \\
Yes & & & & \\
Nausea or vomiting & $81(79.4)$ & $86(86)$ & $87(85.3)$ & & \\
No & $21(20.6)$ & $14(14)$ & $15(14.7)$ & & \\
Yes & & & & \\
Sleepness Sleeplessness & $92(90.2)$ & $94(94)$ & $98(96.1)$ & & \\
No & $10(9.8)$ & $6(6)$ & $4(3.9)$ & & \\
Yes & & & & \\
\hline
\end{tabular}


identification of the injection site and LA diffusion, which would increase the risk of complications associated with TLIP block performed in the postoperative period. However, in our study, we did not find a high rate of contamination among the three groups. No side effects or complications occurred.

This study has some limitations. Frist, all of the patients suffered plane block after general anesthesia was administered, so the scope of analgesia was not described by patients. Second, the lack of data makes it impossible to examine certain acute pain risk factors, such as genetics, race, and anxiety. Our work is a small, randomized trial and is designed to be closely integrated with clinical applications. Therefore, there is a need to investigate preclinical toxicity and clinical application in order to elaborate on the mechanism and provide a maximum benefit while minimizing side effects in peripheral nerve blocks.

\section{CONCLUSIONS}

In conclusion, our results suggest that the addition of ESP block is associated with early analgesic benefits, including a reduction opioid following lumbar fusion surgery.

\section{ACKNOWLEDGEMENTS}

We thank the participants of the study.

Funding. No funding or sponsorship was received for this study or publication of this article. The Rapid Service Fee was funded by the authors.

Authorship. All named authors meet the International Committee of Medical Journal Editors (ICMJE) criteria for authorship for this article, take responsibility for the integrity of the work as a whole, and have given their approval for this version to be published.

Author Contributions. (I) Conception and design: Ke Chen, Lizhen Wang and Yuanhai Li; (II) Administrative support: Ke Chen; (III)
Provision of study materials or patients: Lizhen Wang, Ke Chen; (IV) Collection and assembly of data: Lianjie Dou, Ke Chen; (V) Data analysis and interpretation: Lianjie Dou, Ke Chen; (VI) Manuscript writing: all authors.

Disclosures. Lizhen Wang, Ying Wu, Lianjie Dou, Ke Chen, Yuesheng Liu, and Yuanhai Li have no conflicts of interest to disclose.

Compliance with Ethics Guidelines. This study was approved by the Academic Committee of Anhui Medical University (No. PJ2018-1101) and registered at the Chinese Clinical Trial Registry (ChiCTR1800019639). The study was conducted according to the principles of the Helsinki Declaration. All the data analyzed in our study were retrieved from published literature, and we confirmed that written informed consent was obtained. We confirm that we have read the Journal's position on issues involved in ethical publication and affirm that this report is consistent with those guidelines.

Data Availability. The datasets generated during and/or analyzed during the current study are available from the corresponding author on reasonable request.

Open Access. This article is licensed under a Creative Commons Attribution-NonCommercial 4.0 International License, which permits any non-commercial use, sharing, adaptation, distribution and reproduction in any medium or format, as long as you give appropriate credit to the original author(s) and the source, provide a link to the Creative Commons licence, and indicate if changes were made. The images or other third party material in this article are included in the article's Creative Commons licence, unless indicated otherwise in a credit line to the material. If material is not included in the article's Creative Commons licence and your intended use is not permitted by statutory regulation or exceeds the permitted use, you will need to obtain permission directly from the copyright holder. To view a copy of this licence, visit http://creativecommons.org/licenses/bync/4.0/. 


\section{REFERENCES}

1. Deyo RA, Hallvik SE, Hildebran C, Marino M, O'Kane N, Carson J, Van Otterloo J, Wright DA, Millet LM, Wakeland W. Use of prescription opioids before and after an operation for chronic pain (lumbar fusion surgery). Pain. 2018;159(6):1147-54.

2. Tseng $\mathrm{V}, \mathrm{Xu} \mathrm{JL}$. Erector spinae plane block for postoperative analgesia in lumbar spine surgery: Is there a better option? J Neurosurg Anesthesiol. 2019;33(1):92.

3. Weinstein JN, Tosteson TD, Lurie JD, Tosteson ANA, Blood EA, Hanscom B, Herkowitz HN, Cammisa FP, Albert TJ, Boden SD. Surgical versus nonsurgical therapy for lumbar spinal stenosis. N Engl J Med. 2008;358(8):794-810.

4. Delitto A, Piva SR, Moore CG, Fritz JM, Wisniewski SR, Josbeno DA, Fye M, Welch WC. Surgery versus nonsurgical treatment of lumbar spinal stenosis: a randomized trial. Ann Intern Med. 2015;162(7): 465-73.

5. Simpson JC, Bao X, Agarwala A. Pain management in enhanced recovery after surgery (ERAS) protocols. Clin Colon Rectal Surg. 2019;32(2):121-8.

6. Gerbershagen HJ, Aduckathil S, van Wijck AJM, Peelen LM, Kalkman CJ, Meissner W. Pain intensity on the first day after surgery a prospective cohort study comparing 179 surgical procedures. Anesthesiology. 2013;118(4):934-44.

7. Elsharkawy H, Pawa A, Mariano ER. Interfascial plane blocks: back to basics. Reg Anesth Pain Med. 2018;43(4):341-6.

8. Willard FH, Vleeming A, Schuenke MD, Danneels L, Schleip R. The thoracolumbar fascia: anatomy, function and clinical considerations. J Anat. 2012;221(6):507-36.

9. Machi A, Joshi GP. Interfascial plane blocks. Best Pract Res Clin Anaesthesiol. 2019;33(3):303-15.

10. Hand WR, Taylor JM, Harvey NR, Epperson TI, Gunselman RJ, Bolin ED, Whiteley J. Thoracolumbar interfascial plane (TLIP) block: a pilot study in volunteers. Canadian Journal of Anaesthesia = Journal canadien d'anesthesie. 2015;62(11):1196-200.

11. Forero M, Adhikary SD, Lopez H, Tsui C, Chin KJ. The erector spinae plane block: a novel analgesic technique in thoracic neuropathic pain. Reg Anesth Pain Med. 2016;41(5):621-7.

12. Elsharkawy H, Ince I, Pawa A. Rhomboid intercostal and sub-serratus (RISS) plane block for analgesia after lung transplant. J Clin Anesth. 2019;56:85-7.
13. Adhikary SD, Bernard S, Lopez H, Chin KJ. Erector spinae plane block versus retrolaminar block: a magnetic resonance imaging and anatomical study. Reg Anesth Pain Med. 2018;43(7):756-62.

14. Ahiskalioglu A, Alici HA, Selvitopi K, Yayik AM. Ultrasonography-guided modified thoracolumbar interfascial plane block: a new approach. Canadian Journal of Anaesthesia = Journal canadien d'anesthesie. 2017;64(7):775-6.

15. Chen K, Wang L, Liu X, Lu Y. Ultrasound-guided erector spinae plane block reduces perioperative opioid consumption in lumbar spinal fusion. Am J Ther. 2021;28(2):e266-8.

16. Almeida CR, Oliveira AR, Cunha P. Continuous bilateral erector of spine plane block at T8 for extensive lumbar spine fusion surgery: case report. Pain Pract. 2019;19(5):536-40.

17. Melvin JP, Schrot RJ, Chu GM, Chin KJ. Low thoracic erector spinae plane block for perioperative analgesia in lumbosacral spine surgery: a case series. Canadian Journal of Anaesthesia = Journal canadien d'anesthesie. 2018;65(9):1057-65.

18. Tsui BCH, Kirkham K, Kwofie MK, Tran DQ, Wong P, Chin KJ, Sondekoppam RV. Practice advisory on the bleeding risks for peripheral nerve and interfascial plane blockade: evidence review and expert consensus. Canadian Journal of Anaesthesia = Journal canadien d'anesthesie. 2019;66(11): 1356-84.

19. Brandal D, Keller MS, Lee C, Grogan T, Fujimoto Y, Gricourt Y, Yamada T, Rahman S, Hofer I, Kazanjian K, Sack J, Mahajan A, Lin A, Cannesson M. Impact of enhanced recovery after surgery and opioid-free anesthesia on opioid prescriptions at discharge from the hospital: a historical-prospective study. Anesth Analg. 2017;125(5):1784-92.

20. Hanley C, Wall T, Bukowska I, Redmond K, Eaton D, Róisín Ní Mhuircheartaigh, Conor Hearty. Ultrasound-guided continuous deep serratus anterior plane block versus continuous thoracic paravertebral block for perioperative analgesia in videoscopic-assisted thoracic surgery. Eur J Pain (London, England). 2020;24(4):828-38.

21. Chin KJ, Adhikary S, Sarwani N, Forero M. The analgesic efficacy of pre-operative bilateral erector spinae plane (ESP) blocks in patients having ventral hernia repair. Anaesthesia. 2017;72(4):452-60.

22. Wang MY, Chang P-Y, Grossman J. Development of an Enhanced Recovery After Surgery (ERAS) approach for lumbar spinal fusion. J Neurosurg Spine. 2017;26(4):411-8. 
23. Ciftci B, Ekinci M, Celik EC, Yayik AM, Aydin ME, Ahiskalioglu A. Ultrasound-guided erector spinae plane block versus modified-thoracolumbar interfascial plane block for lumbar discectomy surgery: a randomized. Controlled Study World Neurosurg. 2020;144:e849-55.

24. De Lara González SJ, Pomés J, Prats-Galino A, Gracia J, Martínez-Camacho A, Sala-Blanch X. Anatomical description of anaesthetic spread after deep erector spinae block at L-4. Rev Esp Anestesiol Reanim. 2019;66(8):409-16.

25. Ahiskalioglu A, Yayik AM, Celik EC, Aydin ME, Uzun G. Ultrasound guided modified
Thoracolumbar Interfascial Plane block for low back pain management. J Clin Anesth. 2019;54:138-9.

26. Li C, Jia J, Qin Z, Tang Z. The use of ultrasoundguided modified thoracolumbar interfascial plane (TLIP) block for multi-level lumbar spinal surgery. J Clin Anesth. 2018;46:49-51.

27. Yayik AM, Cesur S, Ozturk F, Ahiskalioglu A, Ay AN, Celik EC, Karaavci NC. Postoperative analgesic efficacy of the ultrasound-guided erector spinae plane block in patients undergoing lumbar spinal decompression surgery: a randomized controlled study. World Neurosurg. 2019;126:e779-85. 